\title{
Microstructure and Mechanical Properties of an Underwater Wet Welded Dissimilar Ferritic/Austenitic Steel Joint
}

\author{
N. Guo, ${ }^{a, b, 1}$ Z. Yang, ${ }^{c}$ M. Wang, ${ }^{a}$ X. Yuan, ${ }^{c}$ and J. Feng ${ }^{a, b}$ \\ ${ }^{a}$ Shandong Provincial Key Laboratory of Special Welding Technology, Harbin Institute of Technology \\ at Weihai, Weihai, China \\ ${ }^{\mathrm{b}}$ State Key Laboratory of Advanced Welding and Joining, Harbin Institute of Technology, Harbin, \\ China \\ ${ }^{c}$ Institute of Oceanographic Instrumentation, Shandong Academy of Sciences, Qingdao, China \\ 1.gn21c@126.com
}

EH40 ship steel was underwater wet-welded by shielded metal-arc welding at a depth of $7 \mathrm{~m}$ in the open sea, using austenitic electrodes. The microstructure and mechanical properties of the joint were estimated with microhardness measurements, bending and tensile testing, optical microscopy, scanning electron microscopy, and energy dispersive X-ray spectroscopy. The highest microhardness was recorded on the coarse-grained heat-affected zone of the base metal, which displayed a mixed bainite-martensite microstructure, while the welds possessed a fully columnar dendritic austenitic structure. The specimens exhibited higher ultimate strength and elongation in longitudinal tensile tests than in transverse ones. Moreover, the specimens satisfied face bending tests but failed in root bending ones. Hydrogen-induced microcracks, which were observed in a lath martensite layer at the fusion boundary, became the fracture initiation region both in bending and transverse tensile tests.

Keywords: EH40 ship steel, underwater welding, austenitic, martensite layer, hydrogen induced microcracks.

Introduction. In recent years, underwater welding becomes increasingly instrumental for the repair and maintenance of hydrotechnical structures, such as submerged pipelines, offshore oil platforms, nuclear power plants, watercrafts, seashore components, piers as well as harbor devices and systems [1, 2]. Underwater welding techniques can be subdivided into two main types: wet and dry. In contrast to dry welding, the wet one requires no complicated experimental set up, whereas the process simplicity makes it possible to weld even the most geometrically complex structures. Thus, wet welding is much more cost-effective, which makes it the obvious choice wherever possible. However, since wet welding is performed at ambient pressure with no physical barrier between water and welding arc, the increased pressure makes welding arc unstable. Moreover, as the contents of oxygen and hydrogen present in the weld pool are higher due to water dissociation in the electric arc, the increasing porosity and hydrogen-induced cracks are produced during underwater wet welding [3]. Due to expectations that the need for underwater structural repair and maintenance of offshore production platforms will grow, the demand for producing high-quality wet welds, including development of wet welding consumables, also continues to increase [4].

In view of the high strength, excellent toughness and good weldability, the EH40 ship steel shows trends of increasing use in the offshore industry, especially when high heat input is applied in welding of thick plates [5] with a low carbon equivalent $\left(C_{e q}\right)$ value. However, the underwater wet weldability of EH40 steel is still unclear. As EH40 steel is a low-carbon, microalloyed steel, martensite microstructures are readily produced in the underwater joints of this steel due to rapid cooling of the weld metal by the surrounding water [6]. Due to its low toughness and hydrogen solubility, martensite is more susceptible to hydrogen- and stress-induced cracking $[7,8]$. In contrast to martensite, austenite has a 
much higher hydrogen solubility, lower hydrogen diffusion rate of hydrogen and higher ductility, which reduces the risk of cracking. In order to minimize the amount of martensite formed in underwater joint, a domestic austenitic 904L typed electrode was used in the present study to investigate the underwater wet welding of EH40 steel. The structural and mechanical properties of the underwater wet welded dissimilar ferritic-austenitic steel joint are discussed.

1. Experimental Procedure. An 904L austenitic typed electrode with rod made of superaustenitic stainless steel 904L was developed for welding of EH40 steel. The base materials were supplied in $14 \mathrm{~mm}$ thick plate for V-groove butt joint configuration, with $45^{\circ}$ groove angle and $7 \mathrm{~mm}$ root opening. The plates were restrained by a backing plate to simulate actual high restraint fabrication conditions. Multipass welds were deposited using the shielded metal arc welding (SMAW) process with $4.0 \mathrm{~mm}$ diameter and $350 \mathrm{~mm}$ long electrodes, being carried out with a welding power source operating with a direct current electrode negative at a nominal 190 A. Welding tests were performed at the immersion depth of $7 \mathrm{~m}$ in the open sea.

In order to investigate the mechanical characteristics of the dissimilar weldment and identify the site of failure, tensile and three-point bending tests were conducted using a universal testing machine (UTM5000, China) with the loading capacity of $500 \mathrm{kN}$ at room temperature. Two types of tensile test specimens were machined from the dissimilar weldment:

(i) transverse tensile specimens containing the weld in the center of the gauge length;

(ii) longitudinal specimen machined along the weld metal.

A gauge length of $50 \mathrm{~mm}$ was used to calculate the elongation. Three-point bending tests were also performed with transverse specimens, including both the face bending (the frontal face of the weld is subjected to tensile stress) and the root bending (the root of the weld is subjected to tensile stress). The bending specimens were cut in the longitudinal direction and had the same configuration as the transverse tensile ones. For preparing the tensile and bending test specimens, the backing plate was removed and the root and face of the welds were grinded. Both tensile and bending tests were conducted at a cross-head velocity of $10 \mathrm{~mm} / \mathrm{min}$. In all tensile and bending tests, each data point represented an average of at least two to four specimens. Vickers hardness test was also conducted at the cross section to study the transition in microstructure of the joint. A diamond pyramid indenter was used with a $0.49 \mathrm{~N}$ load for $15 \mathrm{~s}$.

For microstructural examinations, the welded plate was sectioned perpendicular to the welding direction. Specimens were grinded with 1500-grit emery papers and finally polished by diamond paste down to $1 \mu \mathrm{m}$. Microstructural characterization was performed using the optical metallography (Olympus GX51, Japan), scanning electron microscope (SEM) (Hitachi S-4700), and the attached energy dispersive X-ray spectroscopy (EDS). In view of the range of compositions and microstructures in the weld between ferritic and superaustenitic stainless steels, a number of chemical etchants were used, including $10 \%$ chromic acid, 3\% nital, and a mixture of $5 \mathrm{~g} \mathrm{FeCl}_{3} / 2 \mathrm{ml} \mathrm{HCl} / 90 \mathrm{ml}$ ethanol.

2. Results and Discussion. Figure 1a shows two wet welds made with the austenitic electrode on EH40 steel plate at $7 \mathrm{~m}$ immersion depth. The welds exhibit a good weld bead appearance with quite well-defined ripples, which signify a good arc stability and constant feeding. Moreover, the spatter, which is generated excessively in wet welds, is not observed in the present study.

The cross-sectional morphology of the multi-pass butt-welded joint is presented in Fig. 1b. Clearly, a robust V-groove butt joint is obtained with no solidification cracks or large macrodefects, such as slag inclusions or pores, which are usually presented in underwater wet welds. Moreover, since the thermal cycles of both the heating and cooling phases vary with the distance from the fusion line to the base metal, action of the heating cycle of subsequent passes changes the structure of the HAZ of the previous join. Thus, the 


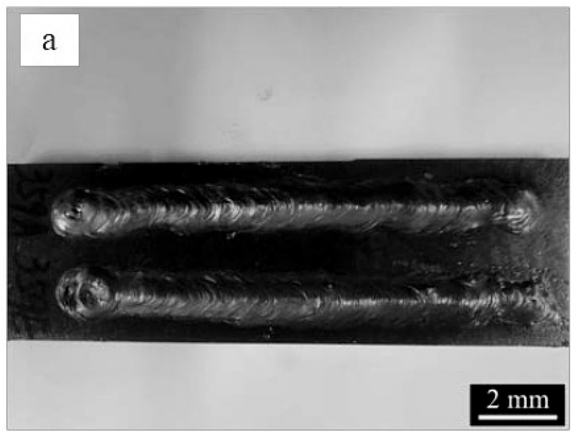

$\mathrm{b}$

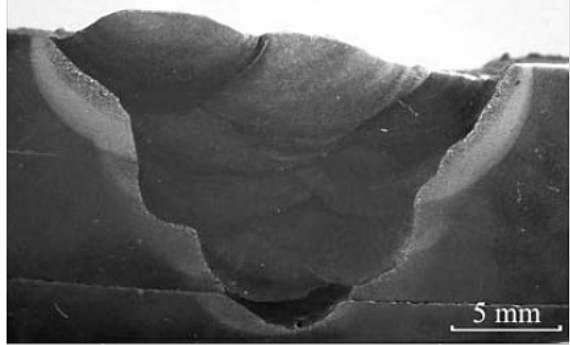

Fig. 1. Welds of austenitic electrode on the EH40 ship steel plate deposited at $7 \mathrm{~m}$ immersion depth: (a) weld surface formation; (b) cross section of the multipass butt-welded joint.

HAZ appearance varies with the weld location, indicating that various microstructures are produced in the HAZ. The maximum HAZ with width of $3.4 \mathrm{~mm}$ is obtained within the cover pass.

The transverse tensile specimens have the average values of the ultimate tensile strength equal to $537.7 \mathrm{MPa}$ and the yield strength equal $421.5 \mathrm{MPa}$, both of which are similar to those of the base metal EH40 steel. In the longitudinal tensile test, the weld metal had the ultimate tensile strength of $543.5 \mathrm{MPa}$, which is somewhate higher than that of the joint determined by the transverse tensile tests. Moreover, the elongation of the austenitic weld metal is higher than that of the dissimilar ferritic/austenitic steel joint: 19.7 and $11.9 \%$, respectively. The above data indicate that a robust weld with a satisfactory joint strength was obtained in underwater wet welding of low alloyed EH40 steel using 904L austenitic typed electrodes.

Figures $2 \mathrm{a}$ and $2 \mathrm{~b}$ show the appearances of the fractured specimens after the tensile test. In the transverse tensile tests, three specimens were broken at the base metal with fracture sites being far from the welds, while the fourth one with a slightly lower ultimate tensile strength of 520.3 MPa was broken at the weld ( see Fig. 2b). Clearly, when applying transverse tensile stress, the cracks were initiated at the fusion boundary of the joint and propagated firstly along the fusion boundary and then into the weld metal, which resulted in the final failure occuring in the weld metal.

In the three-point bending tests, two specimens were approved in face bending tests; however, both of the other two specimens were broken in the root bending tests. Figures $2 \mathrm{c}$ and $2 \mathrm{~d}$ show the appearances of the specimens after the bending tests. According to the enlarged view of the broken joints in root bending tests as shown in the inlet in Fig. 2d, both specimens are cracked along the fusion boundary. No macrodefects such as pores and slag are observed in the broken fusion boundary. In view with the straight cracking at the fusion boundary in transverse tensile test (Fig. 2b), the fracture in Fig. $2 \mathrm{~d}$ can be attibuted the pre-existed microcracks in the fusion boundary of the lower pass. In the face bending tests, the pre-existed microcracks would be subjected to compressive stress and will not no longer propagate. However, under the applied tensile stress in the root bending tests such microcracks would propagate and cause the specimen failure.

In order to clarify possible failure mechanisms, microstructure of the joint and morphology of the fracture surface of the transverse tensile tested specimen were investigated. Figures $3 \mathrm{a}$ and $3 \mathrm{~b}$ illustrate the microstructure of the dissimilar joint. Due to high cooling speed of the underwater wet welding, a fine fully columnar dendritic structure is observed in the weld metal microstructure as shown in Fig. 3a: here the lighter phase is a primary dendritic austenite and the darker one is a secondary interdendritic austenite phase. The primary dendritic austenite grains formed are rich in austenite-stabilizing elements such as $\mathrm{Ni}, \mathrm{N}$, and $\mathrm{C}$, while ferrite-stabilizing elements like $\mathrm{Cr}$, Mo, and $\mathrm{Si}$ accumulate in 

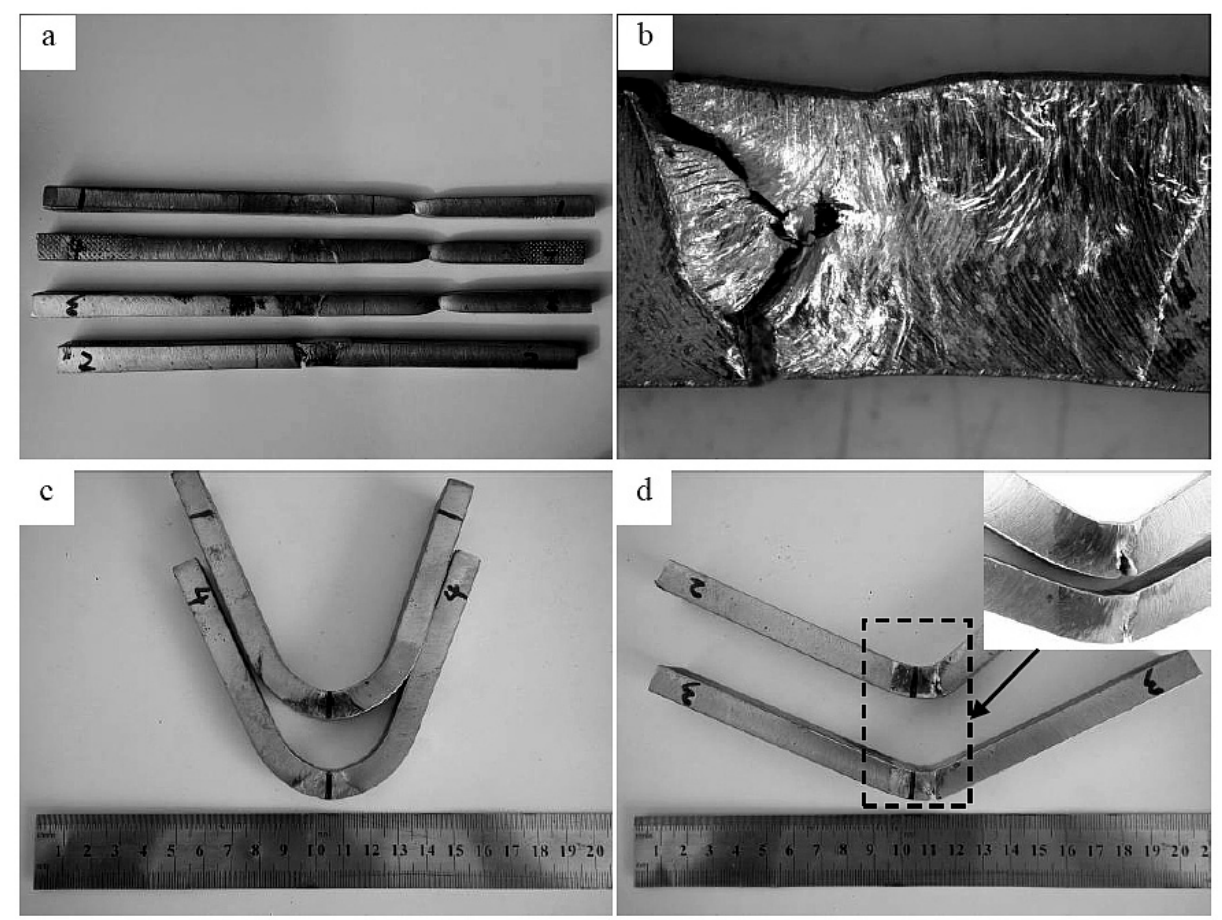

Fig. 2. Broken specimens: (a) fracture site location in tensile tests; (b) enlarged view of a tensile test specimen No.4; (c) specimens after face bending tests; (d) specimens after root bending tests.

the interdendritic liquid phase. However, when this liquid solidifies, the quantities of $\mathrm{Cr}$, Mo, and Si present are not sufficient to form a ferritic structure. A kind of secondary interdendritic austenite is formed, of different composition to the primary austenite, which is clearly visible at the metallographic level. Similar columnar dendritic austenitic structures were also observed in the cases of electron beam and plasma arc welding of superaustenitic stainless steel, where the welds were subjected to fast cooling [9].

Due to significant microstructural embrittlement, the coarse grain heat-affected zone (CGHAZ) of the base low-carbon structural steel is the most susceptible to cracking [10, 11]. However, no cracks were observed in the CGHAZ of the dissimilar ferritic/austenitic steel joint in the present study, as shown in Fig. 3b. The CGHAZ of this joint consists of the upper bainite and martensite with grain size of about $50-100 \mu \mathrm{m}$ and has an average hardness of $394 \mathrm{HV}$, which is significantly higher than that of the base metal ( $206 \mathrm{HV}$ ) and the bulk weld metal $(198 \mathrm{HV})$. Formation of the upper bainite and martensite in CGHAZ is related to the rapid cooling rate in wet welding. Similar to the dissimilar ferritic/austenitic steel joint prepared in air [12], a kind of type II boundary in parallel to the fusion line can be also distinguished in present study, as indicated by the dashed line in Fig. 3b. Moreover, it is clear that the bright layer between the fusion boundary and the type II boundary was not etched after being subjected to chromic acid electrolytic and nital etching.

Cracking along the fusion boundary in dissimilar metal welds has been reported in [13]. In the present study, the dissimilar ferritic/austenitic steel joint also experienced such cracking, as three microscopic cracks of approximately $100 \mu \mathrm{m}$ length are observed in the bright unetched layer near the fusion boundary, as is shown in Fig. 3c. The bright layer was not etched when treated with chromic acid electrolytic etch and nital etch; however, a lath martensitic microstructure was revealed in the bright gray layer when treated with $\mathrm{FeCl}_{3} / \mathrm{HCl} /$ ethanol electrolytic etch, as is shown in Fig. 3d. Due to higher cooling rates in underwater wet welding, a local high dilution would take place near the fusion boundary 


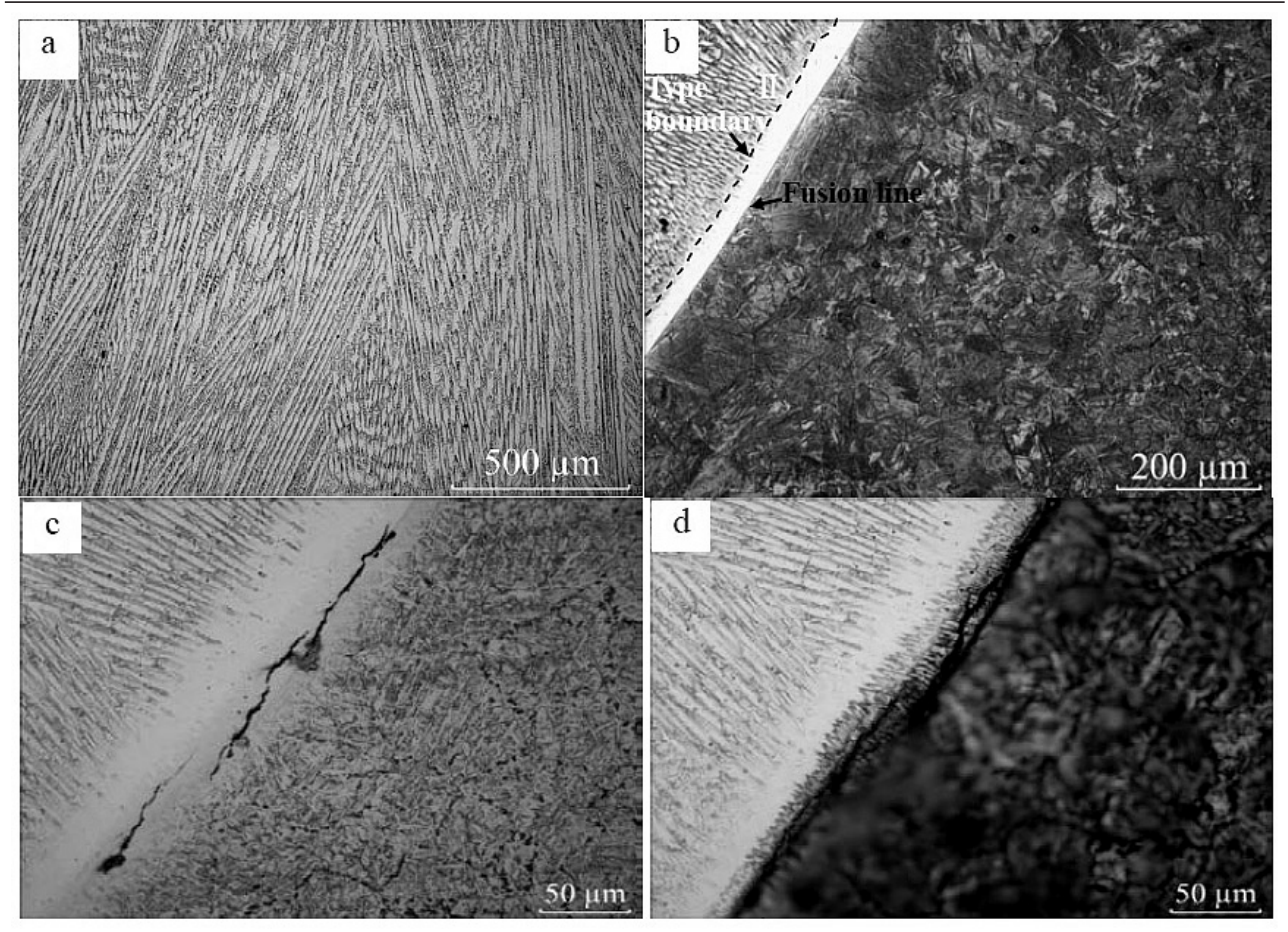

Fig. 3. Optical micrographs of joint: (a) weld metal (b) CGHAZ around the fusion line; (c) chromic acid electrolytic/nital etched surface; (d) chromic acid electrolytic/nital/ferric chloride electrolytic etched surface with a martensitic microstructure near the fusion boundary.

and result in the formation of martensite. Noteworthy is that the exact width of the martensite layer can vary within the given weld due to local variations in the composition gradient and local difference in the cooling rate. Selection of austenitic electrodes with high austenite-forming elements can reduce the tendency to form martensite in both the bulk weld metal, and along the fusion boundary, but it is difficult to eliminate the formation of martensite in the dissimilar joint. In the study of Rowe et al. [13], martensite was also observed near the fusion boundary in underwater wet welding of A36 steel using ERNiCr-3 nickel-based filler metal.

The hydrogen diffusion coefficient in austenitic phase is much lower than that in ferritic phase, and it decreases as the temperature falls, whereas the solubility of hydrogen in austenitic phase is much higher than that in ferritic phase. Thus, high hydrogen content would store at the martensite layer and generate high internal strains [14]. Simultaneously, the pressure resulting from the martensite transformation would accelerate hydrogen diffusion into martensite from the surrounding austenite. However, due to low ductility and solubility of hydrogen, martensite is intrinsically more susceptible to embrittlement. Based on the above consideration, the microcracks in martensite layer are concluded to be hydrogen-induced.

A composition profile was measured across the martensitic gray layer, as shown in Fig. 4, using the EDS line scanning. A dramatic transition in the contents of $\mathrm{Fe}, \mathrm{Cr}$ and $\mathrm{Ni}$ elements occurring at the fusion boundary was recorded. The EDS analysis was also conducted on characteristic positions in weld metal, fusion boundary and CGHAZ, which are shown in Fig. $4 \mathrm{~b}$ as $A, B$, and $C$., respectively. With reference to the WRC-1992 constitution diagram [15], a mixed microstructure of austenite and martensite would be expected to be produced at position $B$, while a fully austenitic microstructure is expected at position $A$. 


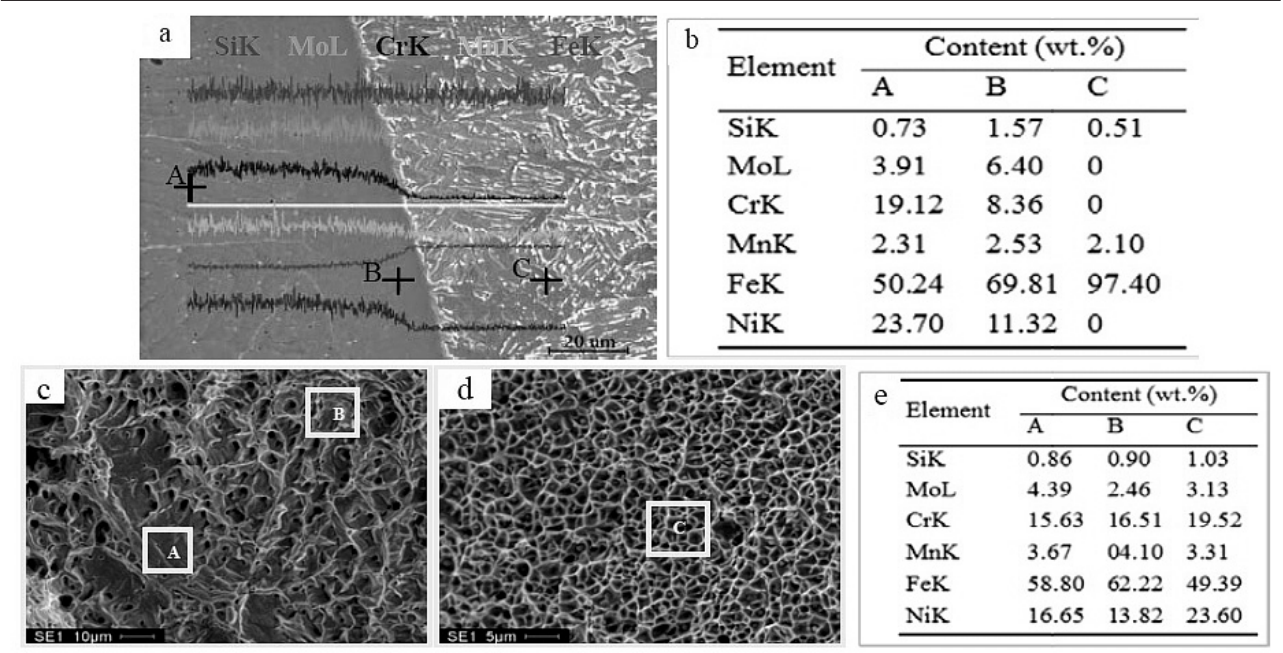

Fig. 4. SEM micrographs and EDS analysis results: EDS of the fusion boundary (a, b), mixed fractured surface at the fusion boundary (c), ductile fractured surface in the weld metal (d); EDS analysis results (e) for the positions marked in (c) and (d).

The fracture surface of the specimen which failed in the weld metal in transverse tensile test was evaluated via SEM, and the micrographs with different morphology are presented in Fig. 4c-e. As shown in Fig. 4c, the fracture surface of the fracture initiation region exhibits a mixed cleavage type with a relatively flat surface and ductile fracture having a dimpled network structure. However, a purely ductile fracture with deep dimples is observed in the broken surface in weld metal, as shown in Fig. 4d. Such difference in fracture models is attributed to the microstructural changes. According to the EDS results shown in Fig. 4e, the contents of $\mathrm{Ni}$ and $\mathrm{Cr}$ elements in areas $A$ and $B$ are intermediate between those in the base metal EH40 steel and the weld metal. In view of the revealed gradient transition in the content of elements around the fusion boundary depicted in Fig. 3c, $\mathrm{d}$, as well as presence of cracks in the lath martensite layer (Fig. $4 \mathrm{a}, \mathrm{b}$ ), the fracture process can be reduced to initiation of microcracks in the martensite layer followed by a mixed fracture pattern resulting from the coexistence of martensitic and austenitic microstructures. Obviously, a purely ductile fracture in the weld metal is related to the fully austenitic microstructure of the weld metal, which is inconsistent with the EDS result for area $C$.

Conclusions. On the basis of this study, the following conclusions can be drawn:

1. A robust weld of EH40 ship steel can be produced by SMAW process using 904L austenitic typed electrodes at $7 \mathrm{~m}$ immersion depth in open sea.

2. As compared to the base metal, the joint manifests a similar ultimate tensile strength in transverse tensile tests and a superior ultimate tensile strength in longitudinal tensile tests.

3. Due to a dramatic transition in the material composition taking place at the fusion boundary of the dissimilar weld, a lath martensite layer is produced at the fusion boundary. The hydrogen-induced cracking in the martensite layer may serve as fracture initiation source in both transverse tensile and bending tests.

Acknowledgments. The authors would like to thank the financial support from the National Natural Science Foundation of China (Grant No. 51005141), the State Key Lab of Advanced Welding \& Joining, Harbin Institute of Technology (AWJ-M13-12), the State Key Development Program for Basic Research of China (Grant No. 2013CB035502) and Weihai Science and Technology Development Planning (Grant No. 2013DXGJ07) for the financial support to this study. 
1. J. Labanowski, "Development of underwater welding techniques," Weld. Int., 25, No. 12, 933-937 (2011).

2. M. Rowe and S. Liu, "Recent developments in underwater wet welding," Sci. Technol. Weld. Join., 6, No. 6, 387-396 (2001).

3. E. C. P. Pessoa, A. Q. Bracarense, E. M. Zica, et al., "Porosity variation along multipass underwater wet welds and its influence on mechanical properties," J. Mater. Process. Technol., 179, 239-243 (2006).

4. V. Santos, M. Monteiro, F. Rizzo, et al., "Development of an oxyrutile electrode for wet welding," Weld J., 91, 319-328 (2012).

5. S. Imai, "Recent progress and future trends for shipbuilding steel," Weld. Int., 22, No. 11, 755-761 (2008).

6. R. D. Manning, Analysis of Underbead Cracking in Underwater Wet Weldments on A516 Grade 70 Steel, DTIC Document (1998).

7. V. Olden, C. Thaulow, and R. Johnsen, Modelling of hydrogen diffusion and hydrogen induced cracking in supermartensitic and duplex stainless steels," Mater. Des., 29, No. 10, 1934-1948 (2008).

8. G. M. Reddy, T. Mohandas, and D. Sarma, "Cold cracking studies on low alloy steel weldments: effect of filler metal composition," Sci. Technol. Weld. Join., 8, No. 6, 407-414 (2003).

9. F. Bonollo, A. Tiziani, R. Tovo, and L. Volpone, "Superaustenitic stainless steels: the microstructure and fatigue strength of welded joints," Weld. Int., 18, No. 1, 24-30 (2004).

10. A. Lambert-Perlade, T. Sturel, A. Gourgues, et al., "Mechanisms and modeling of cleavage fracture in simulated heat-affected zone microstructures of a high-strength low alloy steel," Metall. Mater. Trans. A, 35, 1039-1053 (2004).

11. S. Suzuki, T. Kamo, and Y. Komizo, "Influence of martensitic islands on fracture behaviour of high heat input weld HAZ," Weld. Int., 23, No. 6, 397-402 (2009).

12. T. Nelson, J. Lippold, and M. Mills, "Nature and evolution of the fusion boundary in ferritic-austenitic dissimilar metal welds - Part 2: On-cooling transformations," Weld. Res. Suppl., Oct., 267-277 (2000).

13. M. Rowe, T. Nelson, and J. Lippold, "Hydrogen-induced cracking along the fusion boundary of dissimilar metal welds," Weld. Res. Suppl., Feb., 31-37 (1999).

14. G. Magudeeswaran, V. Balasubramanian, and G. Madhusudhan Reddy, "Hydrogen induced cold cracking studies on armour grade high strength, quenched and tempered steel weldments," Int. J. Hydrogen Energy, 33, No. 7, 1897-1908 (2008).

15. D. Kotecki and T. Siewert, "WRC-1992 constitution diagram for stainless steel weld metals: a modification of the WRC-1988 diagram," Weld. Res. Suppl., May, 171-178 (1992). 